\title{
Supercritical Fluid Extraction of Polyphenols from Vietnamese Callisia fragrans Leaves and Antioxidant Activity of the Extract
}

\author{
Le Thao My Phan $\left(\mathbb{D},{ }^{1}\right.$ Kim Thien Phuc Nguyen, ${ }^{2}$ Hoai Thanh Vuong $\left(\mathbb{D},{ }^{2}\right.$ Do Dat Tran $(\mathbb{D})$, \\ Tran Xuan Phuong Nguyen, ${ }^{3}$ Minh Nam Hoang $\mathbb{D}^{2,4}$ Thanh Phong Mai $\mathbb{D},{ }^{2,4}$ \\ and Huu Hieu Nguyen $\mathbb{D D}^{1,2,4}$ \\ ${ }^{1}$ VNU-HCMC Key Laboratory of Chemical Engineering and Petroleum Processing (CEPP Lab), \\ Ho Chi Minh City University of Technology, 268 Ly Thuong Kiet Street, Ward 14, District 10, Ho Chi Minh, Vietnam \\ ${ }^{2}$ Faculty of Chemical Engineering, Ho Chi Minh City University of Technology, 268 Ly Thuong Kiet Street, Ward 14, District 10, \\ Ho Chi Minh, Vietnam \\ ${ }^{3}$ Hong Bang International University, 215 Dien Bien Phu Street, Ward 15, Binh Thanh District, Ho Chi Minh, Vietnam \\ ${ }^{4}$ Vietnam National University, Linh Trung Ward, Thu Duc District, Ho Chi Minh, Vietnam \\ Correspondence should be addressed to Huu Hieu Nguyen; nhhieubk@hcmut.edu.vn
}

Received 12 April 2020; Revised 2 June 2020; Accepted 22 June 2020; Published 17 July 2020

Academic Editor: Clara Cilindre

Copyright (c) 2020 Le Thao My Phan et al. This is an open access article distributed under the Creative Commons Attribution License, which permits unrestricted use, distribution, and reproduction in any medium, provided the original work is properly cited.

\begin{abstract}
Vietnamese Callisia fragrans (C. fragrans) has been considered as a valuable traditional plant with various medicinal properties. In this study, polyphenols were extracted from Vietnamese $C$. fragrans leaves by supercritical carbon dioxide $\left(\mathrm{SC}-\mathrm{CO}_{2}\right)$ extraction method using ethanol as a cosolvent. The investigation of four factors influencing the total polyphenol content (TPC) and antioxidant activity of the extracts obtained from each single-factor experiment was conducted including ethanol concentration, $\mathrm{CO}_{2}$ flow rate, extraction temperature, and pressure. Besides, the extraction efficiency of the $\mathrm{SC}-\mathrm{CO}_{2}$ method under the best extraction conditions, namely ethanol concentration of $14 \%, \mathrm{CO}_{2}$ flow rate of $20 \mathrm{~g} / \mathrm{min}$, extraction temperature of $45^{\circ} \mathrm{C}$, and pressure of 200 bar was compared to that of the Soxhlet extraction (SE) method in terms of the TPC and antioxidant activity of the extracts. The results showed that using SC- $\mathrm{CO}_{2}$ method, the TPC and the half-maximal inhibitory concentration value obtained were of $87.42 \pm 1.33 \mathrm{mg} / \mathrm{g}$ and $243.83 \pm 5.30 \mu \mathrm{M} \mathrm{TE} / \mathrm{g}$, respectively, with much less time and solvent amount required while that obtained using SE method were of $85.34 \pm 4.27 \mathrm{mg} / \mathrm{g}$ and $236.33 \pm 7.66 \mu \mathrm{M} \mathrm{TE} / \mathrm{g}$, respectively. This indicated that SC-CO $\mathrm{CO}_{2}$ would be suitable for the industrial production of polyphenols with high antioxidant activity of the extracts obtained due to the restrictions of using the SE method and advantages of applying SC- $\mathrm{CO}_{2}$ method. Therefore, SC- $\mathrm{CO}_{2}$ method could be regarded as a potentially upcoming extraction technique which might be employed to replace the conventional SE method.
\end{abstract}

\section{Introduction}

Over 500 species belonging to Commelinaceae family, especially Vietnamese Callisia fragrans (C. fragrans), have been widely grown in eastern Australia to have their leaves and stems harvested [1]. Containing a great variety of bioactive components such as flavonoids, phytosteroids, vitamins, and microelements, this plant has been well known for many pharmaceutical uses including anti-inflammation, pain killers, burn treatment, and cardiovascular drugs [2,3].
Polyphenols, known as secondary metabolites, present commonly in all higher plants with more than 8,000 phenolic structures that were identified and classified into 10 classes in association with its structures [4]. These compounds consist of flavonoids and nonflavonoids. It is reported that there are more than 4,000 flavonoid structures of which 143 are proanthocyanidins that have been found [5]. In terms of nonflavonoids, phenolic acids play a pivotal role and have been seen as derivatives of benzoic acids comprising gallic acid, protocatechuic acid, and derivatives of 
cinnamic acid [6]. In addition, polyphenols have been considered as an antioxidant agent and an anticancer component owing to biological characterizations for the activation of a variety of enzymes and cell receptors [7]. The polyphenols have been widely applied for sunburn prevention because their aromatic-ring structures could affect the absorbance of the UV radiation ranging from 280 to $315 \mathrm{~nm}[8]$.

The solid-liquid extraction method has been divided into two types encompassing conventional and modern technologies. Conventional extraction techniques such as maceration, percolation, and decoction have long been applied in the fields of pharmacy and food industry [9]. Since the fundamental principles of the Soxhlet extraction (SE) method rely on exhaustive extraction leading to higher yields, this technique has been usually utilized in the laboratory due to its limitations of raw materials and well employed mainly for vegetable oil extraction compared to other traditional techniques such as maceration [10]. With the advantage of the amount of solvent reduction, this method could take long extraction time, contribute to pollution problems because of flammable and hazardous solvent consumption, and require strictly high-purity solvents [11]. Because of the development and enhancement of green extraction technologies, the application of ultrasound, microwave, enzyme, and pressurized liquid has been widely used in many parts of the world [12]. Among these methods, the employment of supercritical fluid, especially supercritical carbon dioxide (SC- $\mathrm{CO}_{2}$ ) extraction method, has been globally investigated to extract natural products from plants based on its distinct capacities [13]. For the utilization of supercritical fluid technology, it has been gained the interest of food and pharmaceutical industries due to the prevention of thermal degradation of target compounds [14]. For instance, the industrial levels of $\mathrm{SC}-\mathrm{CO}_{2}$ extraction have been started since the 1970s for decaffeination of tea and coffee [15]. In contrast with polar phenolic structures, the nonpolar carbon dioxide $\left(\mathrm{CO}_{2}\right)$ compound may modify its polarity by the integration of other solvents called cosolvent or modifier such as ethanol to horn the selectivity and extraction yield of final products [16]. According to preliminary studies, temperature and pressure play a pivotal role in the extraction process using $\mathrm{SC}-\mathrm{CO}_{2}[10]$. Besides, cosolvent concentration and $\mathrm{CO}_{2}$ flow rate have been reported as positive factors, having great impacts on extraction yields [17].

In this study, from Vietnamese C. fragrans, based on total polyphenol content (TPC) determination and antioxidant activity investigation of the extracts obtained, the effect of single operational parameters including ethanol concentration, $\mathrm{CO}_{2}$ flow rate, extraction temperature, and pressure on extraction process was evaluated by utilizing ethanol as a cosolvent for $\mathrm{SC}-\mathrm{CO}_{2}$ extraction method. In addition, SE method was carried out in comparison with the $\mathrm{SC}-\mathrm{CO}_{2}$ extraction method to determine the efficient modern extraction method for polyphenols.

\section{Materials and Extraction Methods}

2.1. Materials and Reagents. The leaves of Vietnamese $C$. fragrans were collected from Hoc Mon District, Ho Chi Minh City, Vietnam. After harvesting, the leaves were cleaned and dipped in $70.0 \%$ ethanol before being air-dried for $1 \mathrm{~h}$. Then the leaves were stored in dark bags to prevent polyphenol degradation due to sunlight and transferred immediately to the laboratory in 1 to $1.5 \mathrm{~h}$. By using a dry air oven, the leaves were dried at a temperature of $70^{\circ} \mathrm{C}$ for $3-4 \mathrm{~h}$ until a constant weight was obtained. Before extraction, the leaves were ground to a fine powder with a commercialgrade blender and stored at $-20^{\circ} \mathrm{C}$ for further analysis.

Ethyl acetate $\left(\mathrm{CH}_{3} \mathrm{COOC}_{2} \mathrm{H}_{5}\right)$, ethanol $\left(\mathrm{C}_{2} \mathrm{H}_{5} \mathrm{OH}\right)$, potassium persulfate $\left(\mathrm{K}_{2} \mathrm{~S}_{2} \mathrm{O}_{8}\right)$, and $n$-hexane $\left(\mathrm{C}_{6} \mathrm{H}_{12}\right)$ were supplied by Chemsol, Vietnam. Folin-Ciocalteu reagent and sodium carbonate $\left(\mathrm{Na}_{2} \mathrm{CO}_{3}\right)$ were supplied by Xilong, China. Trolox (6-hydroxy-2,5,7,8-tetramethychroman-2-carboxylic acid), ABTS (2,2'-azino-bis(3-ethylbenzthiazoline-6sulphonic acid), and gallic acid (3,4,5-trihydroxybenzoic acid) were obtained from Aldrich Chemical Co., Gillingham, Dorset, UK.

\subsection{Extraction Methods}

2.2.1. The Removal of Nonpolar Organic Molecules. $500.0 \mathrm{~g}$ of leaf powder of Vietnamese C. fragrans leaves was extracted with $n$-hexane by maceration for 14 days $(1.5 \mathrm{~L}$ of $n$-hexane solvent, each day) at room temperature to remove nonpolar impurities. After that, the leaf powder was shadedried at room temperature for 1 day and marked as LH.

2.2.2. SE Method. To compare the extraction efficiency, $15.0 \mathrm{~g}$ of the leaf powder LH was extracted by the SE method with $350 \mathrm{~mL}$ of ethyl acetate, extraction temperature of $80-85^{\circ} \mathrm{C}$, and extraction time of $6 \mathrm{~h}$. The collected extracts were concentrated under reduced pressure to partly remove solvents by using a vacuum evaporator at a temperature of $35^{\circ} \mathrm{C}$ to obtain crude extract marked as CLE.

2.2.3. $\mathrm{SC}-\mathrm{CO}_{2}$ Extraction Method. $15.0 \mathrm{~g}$ of the leaf powder $\mathrm{LH}$ was filtered and extracted by $\mathrm{SC}-\mathrm{CO}_{2}$ apparatus with the cosolvent ethanol under operational conditions including ethanol concentration $\left(14,16,18\right.$, and $20 \%$, w/w), $\mathrm{CO}_{2}$ flow rate $(12,14,16,18$, and $20 \mathrm{~g} / \mathrm{min})$, extraction temperature $\left(40,45,55\right.$, and $\left.60^{\circ} \mathrm{C}\right)$, and pressure $(100,150,200$, and 250 bar). While one operational parameter was changed, other operational parameters were kept constant. The extract obtained under optimal extraction conditions using $\mathrm{SC}-\mathrm{CO}_{2}$ was marked as CLC.

2.2.4. Effect of Single Factors on TPC. In this study, the influences of four single operational parameters including ethanol concentration, $\mathrm{CO}_{2}$ flow rate, extraction temperature, and pressure were determined according to the TPC and antioxidant activity of the extracts obtained from singlefactor experiments. 
2.2.5. TPC Determination. TPC was determined based on the Folin-Ciocalteu method [12]. Folin-Ciocalteu's reagent was used to oxidize the samples, and the absorbance measurement was read at $760 \mathrm{~nm}$ after $60 \mathrm{~min}$. Gallic acid was used as a standard to create calibration, and TPC was expressed as gallic acid equivalent per gram of dry weight of the Vietnamese $C$. fragrans extract.

2.3. The Antioxidant Activity Investigation of the Extracts. The extracts obtained from each single-factor experiment were tested for antioxidant activity by ABTS $\left(2,2^{\prime}\right.$-azinobis(3-ethylbenzothiazoline-6-sulfonic acid) diammonium) radical cation decolorization assay [18]. The ABTS radical cation (ABTS + ) could be generated by mixing the $2.45 \mathrm{mM}$ potassium persulfate solution and $7 \mathrm{mM}$ ABTS solution with the ratio of $1: 1$. This reaction mixture was then kept in the dark at room temperature for $12-16 \mathrm{~h}$ before use. The absorbance of the sample was read at $734 \mathrm{~nm}$. The Trolox was used as a standard in the antioxidant activity experiments to generate the calibration curve, and the antioxidant activity of the extract was expressed as $\mu \mathrm{mol}$ TE (Trolox equivalent) per gram of dry weight of the Vietnamese C. fragrans extract. The percentage ABTS inhibition was calculated using the following equation:

$$
\text { ABTS inhibition }(\%)=\left(\frac{A_{0}-A_{1}}{A_{0}}\right) \times 100 \% \text {, }
$$

where $A_{1}$ is the absorbance of the sample reaction solution and $A_{0}$ is the absorbance of the free radical solution. $\mathrm{IC}_{50}$ value was the inhibitory concentration of antioxidant needed to decrease the initial radical by $50 \%$. The $\mathrm{IC}_{50}$ values were obtained from the standard curve, and a lower $\mathrm{IC}_{50}$ value represents a stronger ABTS scavenging capacity.

\section{Results and Discussion}

\subsection{Effect of Single Factors on the TPC}

3.1.1. Ethanol Concentration. Figure 1 indicates the effect of ethanol concentration on the TPC and antioxidant activity of the extracts. Experiments were conducted under extraction conditions including extraction temperature of $50^{\circ} \mathrm{C}$, extraction time of $60 \mathrm{~min}, \mathrm{CO}_{2}$ flow rate of $14 \mathrm{~g} / \mathrm{min}$, and pressure of 200 bar. As can be seen from Figure 1, TPC increased from $35.54 \mathrm{mg}$ GAE/g to $37.56 \mathrm{mg} \mathrm{GAE} / \mathrm{g}$ with an increase in ethanol concentration between 10 and $14 \%$ and went down to $30.58 \mathrm{mg}$ GAE/g when ethanol concentration surpassed over $14 \%$. According to preliminary studies, a nonpolar $\mathrm{CO}_{2}$ compound could be modified with a polar solvent such as methanol or ethanol to horn extraction yield. Although methanol might be the most efficient solvent used, it is more toxic compared to ethanol [19]. It was also reported that using ethanol as a binary solvent could lead to an increase in the TPC because of the alteration of its polarity. Besides, the cell permeability would be enhanced by this solvent as ethanol could have an impact on the phospholipid bilayer of the cell membrane [16]. Additionally, kinds of polyphenols extracted by ethanol, as is known from several studies, are strongly dependent on ethanol concentration [20-22]. The antioxidant activity of the extracts experienced an upward trend and reached its maximum value of $181.58 \mu \mathrm{M} \mathrm{TE} / \mathrm{g}$ at an ethanol concentration of $14 \%$. However, as the ethanol concentration continued to rise above $14 \%$, antioxidant activity fell down rapidly. This could be articulated by the strong relationship between ethanol concentration and free radical properties of the crude extract due to the hydroxyl groups of polyphenols [23]. In accordance with other studies, it is revealed that the antioxidant activity of polyphenols has been strongly relevant to its structures [4]. Hence, higher ethanol concentration could be used to improve the effective dissolution of polar polyphenols. However, too high ethanol concentration may lead to dissolving byproduct compounds, resulting in the decrease of antioxidant capacities. Ethanol concentration changes cause solvent physical properties such as dynamic viscosity, density, and dielectric constant modification, influencing the phenolic compound extraction based on previous studies [24]. Therefore, $14 \%$ was chosen as an optimal ethanol concentration for further experiments.

3.1.2. $\mathrm{CO}_{2}$ Flow Rate. Figure 2 presents the effect of the $\mathrm{CO}_{2}$ flow rate on the TPC and antioxidant activity of the extract. To investigate the impact of the $\mathrm{CO}_{2}$ flow rate, polyphenolics were extracted using $10 \%$ ethanol concentration at $50^{\circ} \mathrm{C}$ for $120 \mathrm{~min}$ with pressure of 200 bar. From Figure 2, it can be seen that TPC increased while rising $\mathrm{CO}_{2}$ flow rate and gained the highest value of $65.58 \mathrm{mg} \mathrm{GAE} / \mathrm{g}$ at $20 \mathrm{~g} / \mathrm{min}$. In terms of antioxidant properties, the antioxidant activity of the extracts grew up gradually and peaked at $192.58 \mu \mathrm{M} \mathrm{TE} / \mathrm{g}$ as the highest point with $\mathrm{CO}_{2}$ flow rate value of $20 \mathrm{~g} / \mathrm{min}$. An increase in TPC could be elucidated by an elevation in the quantities of ethanol and $\mathrm{CO}_{2}$ compounds presenting in samples, leading to strong interactions between solvents and target compounds. Additionally, adequate extraction time would positively contribute to the growth of TPC because it is relevant to mass transfer kinetics $[17,25]$. The results would be in agreement with reported research [26]. Hence, the $\mathrm{CO}_{2}$ flow rate of $20 \mathrm{~g} / \mathrm{min}$ was selected as the optimum.

3.1.3. Extraction Temperature. Figure 3 shows the effect of temperature on the TPC and antioxidant activity of the extract. Polyphenols were extracted under extraction conditions including $\mathrm{CO}_{2}$ flow rate of $14 \mathrm{~g} / \mathrm{min}$, extraction time of $120 \mathrm{~min}$, ethanol concentration of $10 \%$, and pressure of 200 bar.

It can be seen that increasing the extraction temperature from 40 to $45^{\circ} \mathrm{C}$ generally increases TPC and antioxidant activity of the extracts with the maximum values of $43.95 \mathrm{mg}$ $\mathrm{GAE} / \mathrm{g}$ and $180.5 \mu \mathrm{M} \mathrm{TE} / \mathrm{g}$, respectively. When the extraction temperature was over $45^{\circ} \mathrm{C}$, a slight decrease in the TPC and antioxidant activity of the extracts could be observed. This phenomenon could be explained due to the fact that as increasing temperature until $45^{\circ} \mathrm{C}$, the TPC elevated because of an increase in diffusion and desorption [19]. Moreover, raising temperature could be ascribed to some aspects such as permeability of cell walls, solubility of targeted 


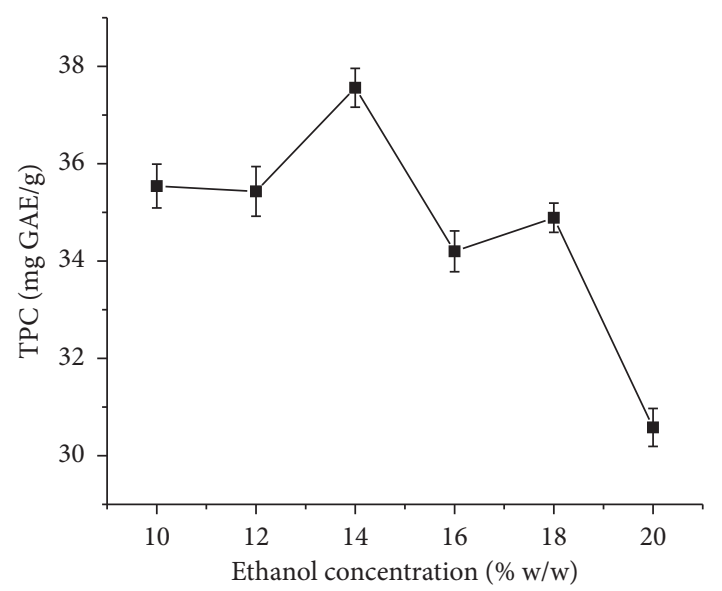

(a)

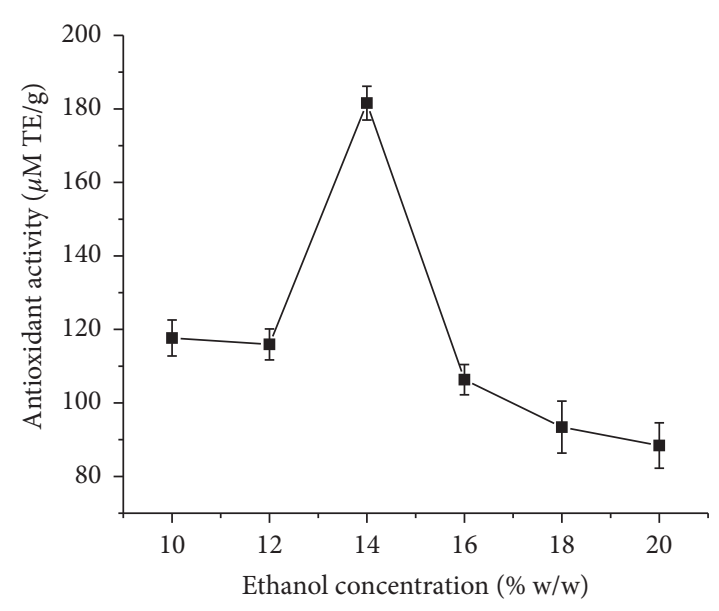

(b)

FIGURE 1: Effect of ethanol concentration (\% w/w) on the (a) TPC (mg GAE/g) and (b) antioxidant activity ( $\mu \mathrm{M}$ TE/g) of the extract.

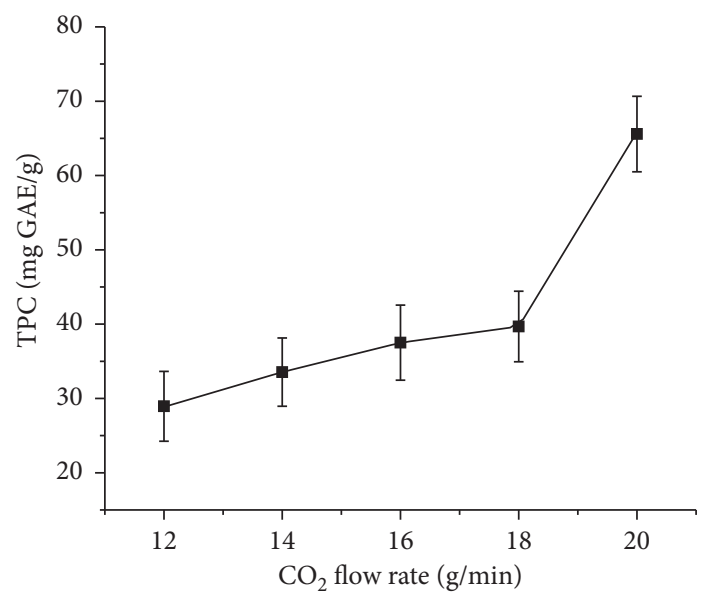

(a)

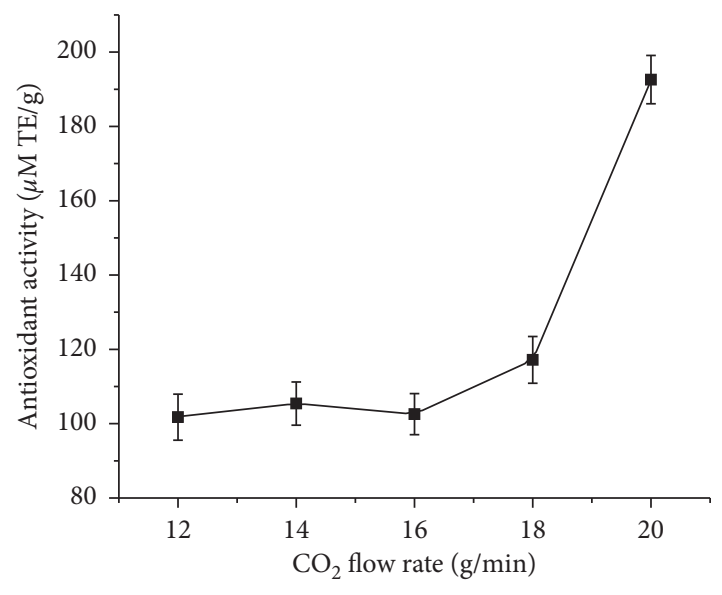

(b)

Figure 2: Effect of the $\mathrm{CO}_{2}$ flow rate (g/min) on the (a) TPC (mg GAE/g) and (b) antioxidant activity ( $\mu \mathrm{M}$ TE/g) of the extract.

compounds, and mass transfer phenomena [16]. It is cited that polyphenols such as anthocyanins are thermally unstable and easily hydrolyzed or oxidized. Hence, it could rapidly degrade by high temperature. In addition, the process of polyphenol hydroxylation and oxidization might induce a decrease in its antioxidant activity of the extracts [27]. The enhancement of temperature has directly exerted a detrimental impact on reducing the density of the modified supercritical $\mathrm{CO}_{2}$, contributing to a decrease of the solubility [28]. This result could be found familiar with other research $[29,30]$. Thus, the extraction temperature of $45^{\circ} \mathrm{C}$ was selected to employ for further research.

3.1.4. Pressure. Figure 4 describes the effect of pressure on the TPC and antioxidant activity of the extract. The influence of pressure on the TPC and antioxidant activity was studied at $100,150,200$, and 250 bars with $\mathrm{CO}_{2}$ flow rate of $14 \mathrm{~g} / \mathrm{min}$, extraction time of $60 \mathrm{~min}$, ethanol concentration of $10 \%$, and extraction temperature of $50^{\circ} \mathrm{C}$. As shown in Figure 4, the TPC and antioxidant activity of the extracts were enhanced and obtained its highest content of $33.55 \mathrm{mg} \mathrm{GAE} / \mathrm{g}$ and $105.41 \mu \mathrm{M} \mathrm{TE} / \mathrm{g}$, respectively, upon increasing pressure to 200 bar, after which a gradual decline in the TPC and antioxidant activity of the extracts could be observed. It is reported that the main important mechanism could be used to explain for this would be the fluid density, which changes the solubility of the solute [31]. Although the density boosts the solvating power of $\mathrm{CO}_{2}$ while increasing pressure, higher pressure could lead to the low mass transfer kinetics due to the low dispersion coefficient of supercritical $\mathrm{CO}_{2}$ as falling diffusivity, negative influence on the highly porous extraction bed, and diminishing in the interaction between solute and solvent.

Thus, extraction efficiency and antioxidant activity decreased sharply [28, 32]. From the previous results, this study might be in consonance with other research [30, 33]. As a result, 200 bar would be set as an optimal pressure. 


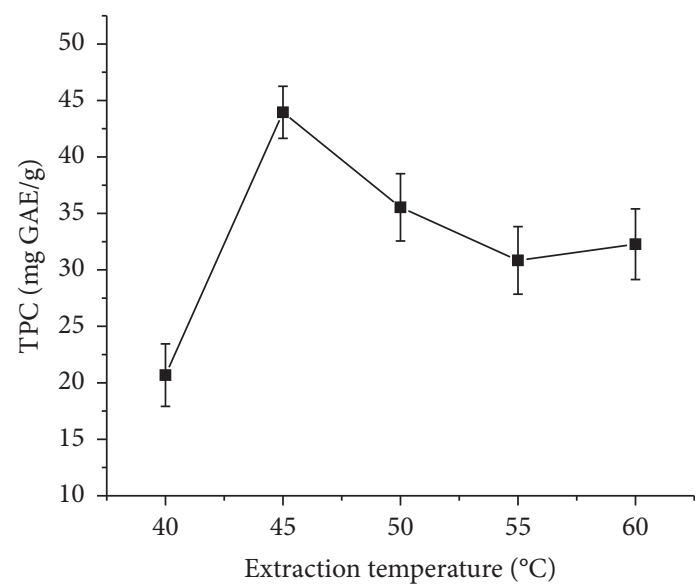

(a)

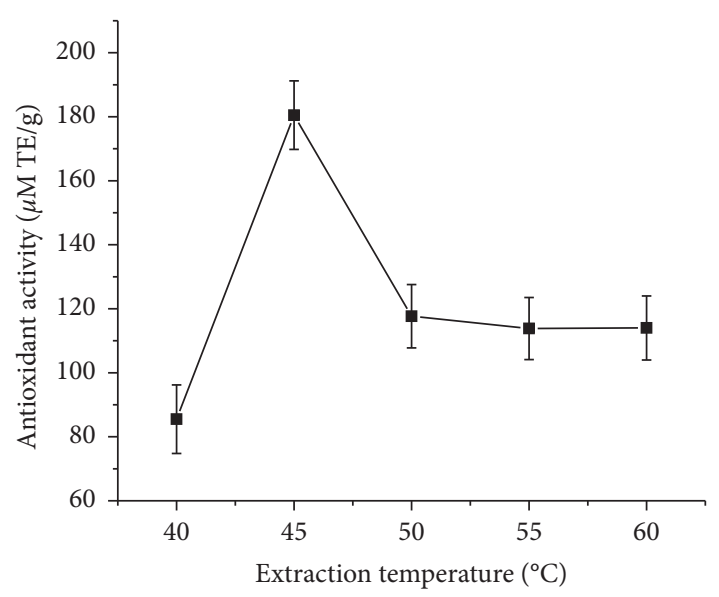

(b)

FIgURE 3: Effect of extraction temperature $\left({ }^{\circ} \mathrm{C}\right)$ on the (a) TPC (mg GAE/g) and (b) antioxidant activity $(\mu \mathrm{M}$ TE/g) of the extract.

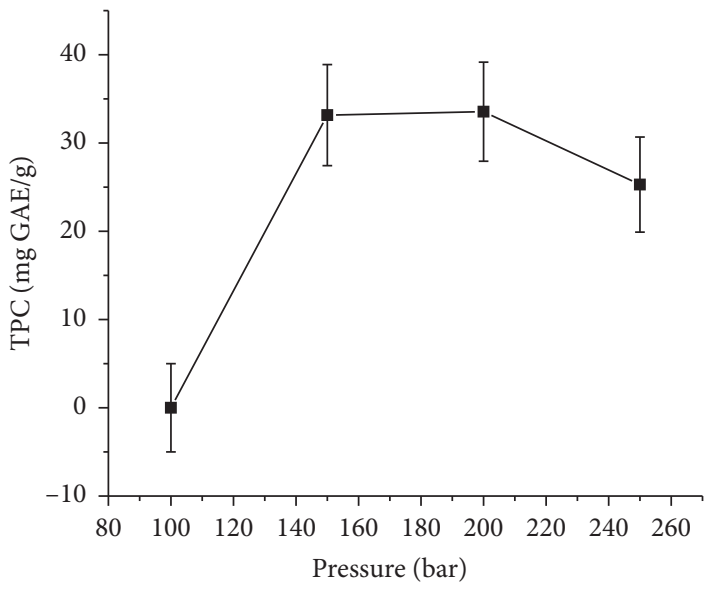

(a)

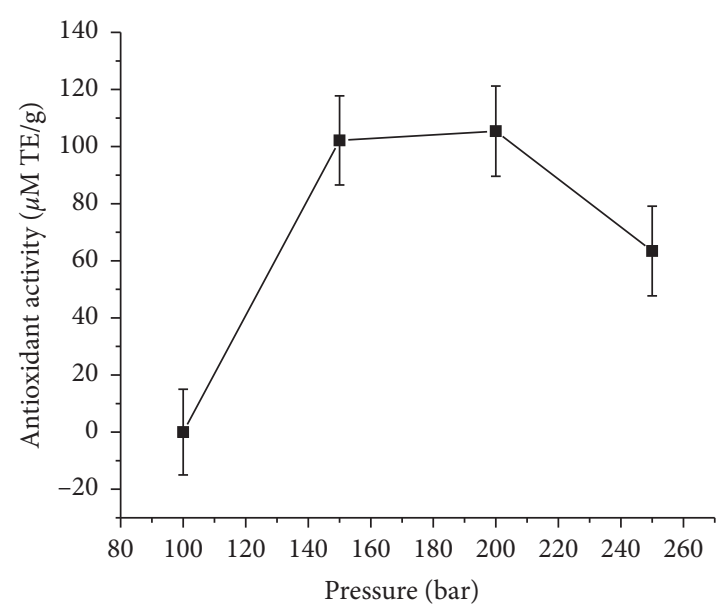

(b)

Figure 4: Effect of pressure (bar) on the (a) TPC (mg GAE/g) and (b) antioxidant activity ( $\mu \mathrm{M}$ TE/g) of the extract.

3.2. SE Method. Table 1 describes the comparison of the TPC and antioxidant activity of the extracts obtained by the SC$\mathrm{CO}_{2}$ and $\mathrm{SE}$ method under conditions of using $350 \mathrm{ml}$ ethyl acetate and temperature ranging from 80 to $85^{\circ} \mathrm{C}$ during 6 hours. The result showed that the TPC and the $\mathrm{IC}_{50}$ value obtained using SC- $\mathrm{CO}_{2}$ method were of $87.42 \pm 1.33 \mathrm{mg} / \mathrm{g}$ and $243.83 \pm 5.30 \mu \mathrm{M} / \mathrm{g}$, respectively, while that obtained using the SE method were of $85.34 \pm 4.27 \mathrm{mg} / \mathrm{g}, 84.60 \mathrm{mg} / \mathrm{g}$, and $236.33 \pm 7.66 \mu \mathrm{M} / \mathrm{g}$, respectively. It is cited that among these conventional techniques, SE has been widely used for polyphenol extraction because employing higher temperature leads to higher mass transfer kinetics as well as continuous change in the transfer equilibrium by the new contact between fresh solvents and solid particles [10]. However, the method could have several restrictions such as long time extraction and volatile as well as flammable organic solvents consumption. These disadvantages might be
TABLE 1: Comparison of the TPC and antioxidant activity of the extracts obtained by the SC-CO 2 and SE method.

\begin{tabular}{lcc}
\hline The extract & TPC $(\mathrm{mg}$ GAE/g) & $\begin{array}{c}\text { Antioxidant activity } \\
(\mu \mathrm{M} \mathrm{TE} / \mathrm{g})\end{array}$ \\
\hline SC- $\mathrm{CO}_{2}$ extract & $87.42 \pm 1.33$ & $243.83 \pm 5.30$ \\
SE extract & $85.34 \pm 4.27$ & $236.33 \pm 7.66$ \\
\hline
\end{tabular}

altered by $\mathrm{SC}-\mathrm{CO}_{2}$, which could generate an improvement in extraction yields and antioxidant activity [11]. In application scale, with limitation on the amount of materials used, SE could not be scalable compared to $\mathrm{SC}-\mathrm{CO}_{2}$ as $\mathrm{SC}-\mathrm{CO}_{2}$ may be suitable for the large quantity of mass production without contaminating products with solvent residues [34]. This result is consistent with reported studies $[3,35,36]$. 


\section{Conclusions}

From Vietnamese C. Fragrans, based on the highest TPC and antioxidant activity of the extract obtained from each singlefactor experiment, the extraction conditions determined with the application of $\mathrm{SC}-\mathrm{CO}_{2}$ method using ethanol as a cosolvent were ethanol concentration of $14 \%, \mathrm{CO}_{2}$ flow rate of $20 \mathrm{~g} / \mathrm{min}$, extraction temperature of $45^{\circ} \mathrm{C}$, and pressure of 200 bar. Under these conditions, the extract was compared with that obtained under the SE method in terms of TPC and antioxidant activity. The results showed that the TPC and the antioxidant activity with $\mathrm{IC}_{50}$ values of the extract obtained using $\mathrm{SC}-\mathrm{CO}_{2}$ method were of $87.42 \pm 1.33 \mathrm{mg} / \mathrm{g}$ and $243.83 \pm 5.30 \mu \mathrm{M} \mathrm{TE} / \mathrm{g}$, respectively, while that obtained using the SE method were of $85.34 \pm 4.27 \mathrm{mg} / \mathrm{g}$ and $236.33 \pm 7.66 \mu \mathrm{M} \mathrm{TE} / \mathrm{g}$, respectively. In terms of polyphenol composition determination by HPLC method for isolation and purification of polyphenol compounds, further research would be conducted in the next study. Therefore, $\mathrm{SC}-\mathrm{CO}_{2}$ method could be considered as a potential efficient extraction method in comparison with the conventional SE method.

\section{Data Availability}

The data used to support the findings of this study are included within the article.

\section{Conflicts of Interest}

The authors declare that they have no conflicts of interest.

\section{Acknowledgments}

The authors acknowledge the support of time and facilities from Ho Chi Minh City University of Technology (HCMUT), VNU-HCM, for this study.

\section{References}

[1] E. L. Susan and K. V. Mason, "Case report Immediate hypersensitivity to leaf extracts of Callisia fragrans (inch plant) in a dog," Veterinary Dermatology, vol. 17, pp. 70-80, 2006.

[2] T. V. Chernenko, N. T. Ul'chenko, A. I. Glushenkova, and D. Redzhepov, "Chemical investigation of Callisia fragrans," Chemistry of Natural Compounds, vol. 43, 2007.

[3] D. N. Olennikov, T. A. Ibragimov, I. N. Zilfikarov, and V. A. Chelombit'ko, "Chemical composition of Callisia fragrans juice 1. Phenolic compounds," Chemistry of Natural Compounds, vol. 44, 2008.

[4] L. Bravo, "Polyphenols: chemistry, dietary sources, metabolism, and nutritional significance," Nutrition Reviews, vol. 56 , no. 11 , pp. $317-333,1998$.

[5] J. B. Harborne, The Flavonoids: Advances in Research Since 1980, Springer, Berlin, Germany, 2013.

[6] M. Daglia, "Polyphenols as antimicrobial agents," Current Opinion in Biotechnology, vol. 23, no. 2, pp. 174-181, 2012.

[7] C. Manach, A. Scalbert, C. Morand, C. Rémésy, and L. Jiménez, "Polyphenols: food sources and bioavailability," The American Journal of Clinical Nutrition, vol. 79, no. 5, pp. 727-747, 2004.
[8] V. Wilfred and N. Ralph, Phenolic Compound Biochemistry, Springer, Berlin, Germany, 2006.

[9] Q.-W. Zhang, Li-G. Lin, and W.-C. Ye, "Techniques for extraction and isolation of natural products: a comprehensive review," Chinese Medicine, vol. 13, 2018.

[10] M. A. Rostagno and J. M. Prado, Natural Product Extraction Principles and Applications, The Royal Society of Chemistry, London, UK, 2013.

[11] N. N. Azwanida, "A review on the extraction methods use in medicinal plants, principle, strength and limitation," Medicinal \& Aromatic Plants, vol. 4, pp. 1-6, 2015.

[12] J. Azmir, I. S. M. Zaidul, M. M. Rahman et al., "Techniques for extraction of bioactive compounds from plant materials: a review," Journal of Food Engineering, vol. 117, no. 4, pp. 426-436, 2013.

[13] H. Nguyen Di Son, T. H. Vi, C. T. Hieu, and N. H. Hieu, "Supercritical fluid extraction of neem seed oil and its ability to inhibit microorganisms," Vietnam Journal of Chemistry, vol. 55, pp. 16-22, 2017.

[14] J. Lindy, Supercritical Fluid Extraction Technology, Applications and Limitations, Nova Science Publishers, Hauppauge, NY, USA, 2015.

[15] F. Chemat, M. Abert Vian, A.-S. Fabiano-Tixier et al., "A review of sustainable and intensified techniques for extraction of food and natural products," Green Chemistry, vol. 22, no. 8, pp. 2325-2353, 2020.

[16] R. R. Watson, Polyphenols in Plants Isolation, Purification and Extract Preparation, Andre Gerhard Wolff, Amsterdam, Netherlands, 2019.

[17] Z. Huang, L. Xu, J.-H. Li, S. Kawi, and A. H. Goh, "Organic template removal from hexagonal mesoporous silica by means of methanol-enhanced $\mathrm{CO}_{2}$ extraction: effect of temperature, pressure and flow rate," Separation and Purification Technology, vol. 77, no. 1, pp. 112-119, 2011.

[18] N. Pellegrini, A. Proteggente, A. Pannala, M. Yang, C. RiceEvans, and R. Re, "Antioxidant activity applying an improved ABTS radical cation decolorization assay," Free Radical Biology and Medicine, vol. 26, pp. 1231-1237, 1999.

[19] F. Le Floch, M. T. Tena, A. R'́os, and M. Valcárcel, "Supercritical fluid extraction of phenol compounds from olive leaves," Talanta, vol. 46, no. 5, pp. 1123-1130, 1998.

[20] K. Ty'skiewicz, M. Konkol, and R. Edward, "Review the application of supercritical fluid extraction in phenolic compounds isolation from natural plant materials," Moleculars, vol. 23, pp. 1-27, 2018.

[21] K. Waszkowiak and A. Gliszczyńska-Świgło, "Binary ethanol-water solvents affect phenolic profile and antioxidant capacity of flaxseed extracts," European Food Research and Technology, vol. 242, no. 5, pp. 777-786, 2016.

[22] C. Sun, Z. Wu, Z. Wang, and H. Zhang, "Effect of ethanol/ water solvents on phenolic profiles and antioxidant properties of Beijing propolis extracts," Evidence-Based Complementary and Alternative Medicine, vol. 2015, Article ID 595393, 9 pages, 2015.

[23] V. Sendamangalam, O. K. Choi, Y. Seo, and D.-S. Kim, "Antimicrobial and antioxidant activities of polyphenols against Streptococcus mutans," Free Radicals and Antioxidants, vol. 1, no. 3, pp. 48-55, 2011.

[24] J. E. Cacace and G. Mazza, "Optimization of extraction of anthocyanins from black currants with aqueous ethanol," Journal of Food Science, vol. 68, no. 1, pp. 240-248, 2003.

[25] G. Camila, M. O. M. Marques, A. S. Barreto, E. C. Fernandes, and M. A. Meireles, "Extraction of indole 
alkaloids from Tabernaemontana catharinensis using supercritical $\mathrm{CO} 2+$ ethanol: an evaluation of the process variables and the raw material origin," The Journal of Supercritical Fluids, vol. 30, pp. 51-61, 2004.

[26] J. P. Maran, S. Manikandan, B. Priya, and P. Gurumoorthi, "Box-Behnken design based multi-response analysis and optimization of supercritical carbon dioxide extraction of bioactive flavonoid compounds from tea (Camellia sinensis L.) leaves," Journal of Food Science and Technology, vol. 52, no. 1, pp. 92-104, 2013.

[27] R. R. Watson, Polyphenols in Plants: Isolation, Purification, and Extract Preparation, Elsevier, Amsterdam, Netherlands, 2014.

[28] C. Da Porto, D. Decorti, and A. Natolino, "Water and ethanol as co-solvent in supercritical fluid extraction of proanthocyanidins from grape marc: a comparison and a proposal," The Journal of Supercritical Fluids, vol. 87, pp. 1-8, 2014.

[29] P. Pereira, M.-J. Cebola, M. C. Oliveira, and M. G. BernardoGil, "Supercritical fluid extraction vs conventional extraction of myrtle leaves and berries: comparison of antioxidant activity and identification of bioactive compounds," The Journal of Supercritical Fluids, vol. 113, pp. 1-9, 2016.

[30] M.-K. Roh, M. S. Uddin, and B.-S. Chun, "Extraction of fucoxanthin and polyphenol from Undaria pinnatifida using supercritical carbon dioxide with co-solvent," Biotechnology and Bioprocess Engineering, vol. 13, no. 6, pp. 724-729, 2008.

[31] L. Uddin, B. Yang, X. Du, and C. Yi, "Optimisation of supercritical fluid extraction of flavonoids from Pueraria lobata," Food Chemistry, vol. 108, no. 2, pp. 737-741, 2008.

[32] M. D. Macías-Sánchez, J. M. Fernandez-Sevilla, F. G. A. Fernández, M. C. C. García, and E. M. Grima, "Supercritical fluid extraction of carotenoids from Scenedesmus almeriensis," Food Chemistry, vol. 123, no. 3, pp. 928-935, 2010.

[33] J. C. W. Ouédraogo, C. Dicko, F. B. Kini, Y. L. Bonzi-Coulibaly, and E. S. Dey, "Enhanced extraction of flavonoids from Odontonema strictum leaves with antioxidant activity using supercritical carbon dioxide fluid combined with ethanol," The Journal of Supercritical Fluids, vol. 131, pp. 66-71, 2018.

[34] N. Bukhanko, T. Attard, M. Arshadi et al., "Extraction of cones, branches, needles and bark from Norway spruce (Piceaabies) by supercritical carbon dioxide and soxhlet extractions techniques," Industrial Crops \& Products, vol. 145, pp. 1-11, 2020.

[35] A. I. Glushenkova, D. Redzhepov, and T. V. Chernenko, "Chemical investigation of Callisia fragrans," Chemistry of Natural Compounds, vol. 43, no. 3, pp. 253-255, 2007.

[36] I. N. Zilficarov, A. A. Toronova, T. A. Ibragimov, and D. N. Olennikov, "Chemical composition of Callisia fragrans juice and it's antioxydant activity in vitro," Chemistry of Natural Compounds, vol. 44, no. 4, pp. 95-100, 2008. 